\title{
Research on Male and Female Youth Perceptions on the Use of Pornographic Displays in Social Media
}

\author{
M. S. N. Abu Hassan, N. H. Ismail, N. S. Abd Halim, M. Abd Aziz, N. H. Mohd Sidik, M. K. A. \\ Kamarudin, N. Abu Bakar, A. B. H. M. Maliki
}

\begin{abstract}
The internet is one of the basic needs of everyone's life. The internet can be easily accessed anywhere with the uses of smartphones in which people can obtain any information and current news by the fingertip. Pornography is estimated to be one of the most frequent search topics on the Internet. This research is being conducted through a quantitative method which is a surveying method that uses a questionnaire that includes a profile of sexual behavior and using the Pornography Consumption Inventory (PCI) questionnaire. This questionnaire was distributed to 1340 respondent that come from the youth of man and woman between age 15 until 40 in Malaysia. The research use Z-test analysis method which is $N=421$ for male and $N=919$ for female. The outcome of this research that was being analysed using Z-test show a significant difference of mean score from four factors which are Sexual Curiosity (SC), Emotional Avoidance (EA), Excitement Seeking (ES), and Sexual Pleasure (SP) between gender. Based on the Ztest, the p-value of all factors is $\mathbf{< 0 . 0 0 0 1}$ which is less than 0.05 .
\end{abstract}

Index Terms:- Consumption, gender, pornography, sexual behaviour, social media, youth.

\section{INTRODUCTION}

The pornography industry has been grown since the 1950's. It started with the release of Playboy magazine. It also the first time magazine from America contains pictures of sexy and beautiful women. After that since the 1970's, many magazines whose contents contain pornographic materials has been released by printing companies. Meanwhile, in late of 1960's, pornographic films were released at America. In the mid1980's, pornographic magazines and publishing companies experiencing the decline due to introducing of new

Revised Manuscript Received on July 10, 2019.

M. S. N. Abu Hassan, Faculty of Applied Social Sciences, Universiti Terengganu, Malaysia.

N. H. Ismail, Faculty of Applied Social Sciences, Universiti Sultan Zainal Abidin, Gong Badak Campus, 21300 Kuala Nerus, Terengganu, Malaysia.

N. S. Abd Halim, Faculty of Applied Social Sciences, Universiti Sultan Zainal Abidin, Gong Badak Campus, 21300 Kuala Nerus, Terengganu, Malaysia.

M. Abd Aziz, Faculty of Applied Social Sciences, Universiti Sultan Zainal Abidin, Gong Badak Campus, 21300 Kuala Nerus, Terengganu, Malaysia.

N. H. Mohd Sidik, Faculty of Applied Social Sciences, Universiti Sultan Zainal Abidin, Gong Badak Campus, 21300 Kuala Nerus, Terengganu, Malaysia.

M. K. A. Kamarudin, Faculty of Applied Social Sciences, Universit Sultan Zainal Abidin, Gong Badak Campus, 21300 Kuala Nerus, Terengganu, Malaysia.

N. Abu Bakar, Faculty of Applied Social Sciences, Universiti Sultan Zainal Abidin, Gong Badak Campus, 21300 Kuala Nerus, Terengganu, Malaysia.

A. B. H. M. Maliki, Faculty of Applied Social Sciences, Universiti Sultan Zainal Abidin, Gong Badak Campus, 21300 Kuala Nerus, Terengganu, Malaysia. Sultan Zainal Abidin, Gong Badak Campus, 21300 Kuala Nerus,

technologies especially with the development of video cassette recorders (VCRs) and television channels. The people more excited and more prefer to choose pornographic films to obtain pornographic material [1].

Since the 1990's, after the growing network of internet, the provision of pornography has been increasing either in America or in other countries. Pornography in America is a business that gives greater profit by earning million dollar assets. In 1996, Americans spent hundreds of millions dollars on pornographic materials such as videos, adult app programs, pornographic computers, sex magazines, and pornographic shows. There are about 25,000 selling pornography videos. In 1992, America had sold 490 million pieces of pornographic videos, compared in 1985 they were sold the pornographic videos only 75 million pieces. In 1997, a survey the internet said there were about 34000 websites. From the other studies told that there were organizations involved in the spread of pornography to the people in certain places [1].

The internet has made a lot of change in communication between people after 40 years people live with television [2]. Nowadays, after the internet brings up the change to people, the internet has been considered one of the most likely to bring danger to individuals and society [3]. However, the use of the internet is very important in the context of the new millennium communication. This is because the internet gives a variety of application that facilitates the process of delivering and receiving information to all people in the world. From the sociological perspective highlighted by the increased use of media technology among people in the majority of daily activities, it was increased in satisfying the free time of people [4]. This study aims to compare male and female youth perceptions on the use of pornographic displays in social media.

\section{MATERIAL AND METHOD}

\section{A. Participants}

This study involved a total of 1340 respondent $\mathrm{N}=421$ for male and $\mathrm{N}=919$ for female. Respondent were selected using stratified random sampling [5]. They consist male and female youth aged 15 until 40 years old. Among the respondents, 155 or $12 \%$ are from 15 to 19 years old, 1089 or $81 \%$ are from 20 to 24 years old, and 80 or $6 \%$ are from 25 to 29 years old. Only 16 or $1 \%$ respondents are 30 years

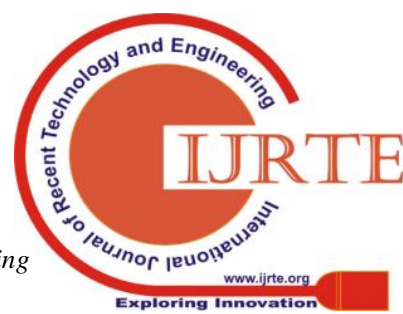




\section{RESEARCH ON MALE AND FEMALE YOUTH PERCEPTIONS ON THE USE OF PORNOGRAPHIC DISPLAYS IN SOCIAL MEDIA}

old and above. They are coming from the variety of state in Malaysia such as Terengganu, Kelantan, Selangor, Sabah, Sarawak, Perlis, Kedah, Pulau Pinang, Johor, Perak, Negeri Sembilan, Wilayah Persekutuan, Melaka, and Pahang.

\section{B. Instrument}

Survey research is a descriptive approach being widely used in research to collect data and information obtained through questionnaires. This instrument is used to identify the addiction level of an individual toward pornography display in social media. The study procedure is carried out in accordance with the policies, rules, university and institute guidelines, and with participants' consent by anonymously completing demographic and early questionnaires pool items for PCI. This questionnaire consists of 2 parts namely A and B. Part A is about demographic information: gender, age, date of birth, marital status, lineage, religion, district, and state while in part B is about the use of pornography among people [5], [6].

\section{Statistical Analysis}

Reprocessing data: A matrix set of youth contains 3452 matrices data (4 variables $\times 863$ youth) were computed in this study. For matrices that have very small amounts of data lost $(\sim 3 \%)$ than the overall data recorded, the nearest neighboring method can be used [7]-[9]. This method examines the distance between each point and its nearest point [10]. The nearest neighboring method is the simplest method, where th endpoint of the gap is used as an estimate of all missing values [11], [12]. In this study, the researcher used a Z-test analysis method. Z-test is one of the statistical distribution. According to centrally-bound theory, data with large sample sizes will be distributed normally. Therefore, Z-test can be used to test large sample data [13]. The number of samples 30 or more is considered a great example. In addition, Z-test is used to analyse the data for which variance is known. However, if population variance is unknown, sample variance cannot be used [14].

\section{RESULTS AND DISCUSSION}

Table 1 showed the statistical use of pornography between sexes for factors Sexual Curiosity, Emotional Avoidance, Excitement Seeking and Sexual Pleasure including minimum, maximum and mean. Minimum for all factors is 1 while the maximum is 5. For Sexual Curiosity factor, the highest mean for the male is F4 variable (2.2898) and the lowest mean is F1 (2.2019) while the highest mean for the female is F4 variable (1.5462) and the lowest mean is at F13 (1.5049). For the Emotional Avoidance factor, the highest mean for the male is F2 (2.0476) and the lowest mean is F10 (1.9786) while the highest mean for the female is F2 (1.4113) and the lowest mean is F15 (1.2927). For the Excitement Seeking factor the highest mean for the male is F6 (2.1425) and the lowest mean is F5 (2.0903) while the highest mean for the female is F6 (1.3950) and lowest mean is F5 (1.3667). For the Sexual Pleasure factor, the highest mean for the male is F7 (2.0926) and the lowest mean is F14 (2.0523) while the highest mean for the female is F7 (1.3830) and the lowest mean is F14 (1.3101). Table 2 shows that there is a significant difference in sex to the tests that test hypotheses are approached with a normal

factor of pornographic use in social media when all the variable shows the $p$-value is $<0.0001$. The highest rate of difference for the Sexual Curiosity factor is F1 "I use it to learn more about a sexual activity" (0.6818). The highest rate of difference for the Emotional Avoidance factor is F15 "I use it to disconnect from unpleasant circumstances or situations I experience" (0.693). The highest rate of difference for the Excitement Seeking factor is F11 "It gives me a sense of excitement" (0.7476). The highest rate of difference for Sexual Pleasure is F14 "I use it to help me masturbate for a physical release" (0.7421). Some of the negative effects of pornography are tended against gender. For example, studies also show that not only are males involved in the use of pornography in social media, but women are also involved in the use of pornography. Negative effects on women involve a bad view of their selfesteem if involved with the use of pornography [15], [16]. Other studies have found that men watching sexual media are closely related to their sexual satisfaction, wanting to know about sexual depictions and their influence on the environment. For women, watching sex has a positive impact on married sexual satisfaction [17]. Gender differences here may be due to the negative impact of pornography on men's sexual impression and sexuality assessment of their own, while the use of pornography for women may help them understand their own physical form and are more likely to have sex with their partners rather than doing alone for the purpose of masturbation [18].

The mainstream in the perspective of feminism is to reject moral views and the views of conservatives. In this case, according to pornography feminism is not about sex but about power. Pornography reflects and strengthens the power of men and sexuality to portray women as sex objects, to satisfy the sexual satisfaction of men. A group of feminists supports restrictions on pornography, but some others do not. Feminism rejecting censorship of pornography expressed and believes that such rule will encourage the repressive attitude. According to this group, all forms of censorship would endanger women's equality. Table 1 showed that mean of usage on pornography display are a difference between male and female. Mean for male 2.0926 and female 1.3830. It is the highest value compare the other question. This shows that male is more likely to find the fun if they use pornography.

However, there are also among the users of this social networking site certainly has a high level of interest to interact in a virtual space, and it is in fact not caused by a sense of loneliness or feelings of shame and to eliminate emotional stress. Based on the results obtained in (Table 1), mean of emotional avoidance shows that young men are more prone to emotional stress factors to get rid of when they use pornography than female youth. With the advent of social networking is all-powerful, it occurs when individuals seek sexual satisfaction or meet the desires frequently or repeatedly [19]. This is because people want to feel the appreciation and enjoyment in doing sexual behavior such as sex, masturbation, watching pornography, erotic images,

Published By:

Blue Eyes Intelligence Engineering 
read the obscene stories, and so as a result of instinct latent in themselves. As a result of the study found that sexual pleasure factor is more likely to be male than female youth based on the mean (Table 1). The issue involved, namely the display of pornography is certainly a negative thing because of indulgences, it is channeled through a wrong way of doing sexual behavior is not in proper condition but masturbation, premarital sex, watch videos and so on. This matter could have a negative impact that will be incurred as health problems, psychological problems such as depression, anxiety, and stress. Social relations for individuals who engage in sexual addiction may also be affected by the lack of confidence and lack of self-control. The younger generation is exposed to various forms of information coming from all over the world via the Internet. Information obtained in the form of literature, images and videos sometimes contain values that are contrary to the norms of the Eastern community.

Table 1: Descriptive statistics on pornography display each variable variation between sexes

\begin{tabular}{|c|c|c|c|c|}
\hline \multirow[b]{2}{*}{ Variables } & \multicolumn{2}{|c|}{ Male } & \multicolumn{2}{|c|}{ Female } \\
\hline & Mean & $\begin{array}{c}\text { Std. } \\
\text { Deviation }\end{array}$ & Mean & $\begin{array}{c}\text { Std. } \\
\text { Deviation }\end{array}$ \\
\hline \multicolumn{5}{|l|}{ Factor 1: Sexual Curiosity } \\
\hline Q1: I use it to learn more about a sexual activity. & 2.20 & 1.28 & 1.52 & 0.86 \\
\hline Q4: I'm curious about what type of sex other people have. & 2.29 & 1.30 & 1.55 & 0.92 \\
\hline Q8: I use it to expand my knowledge about sexual possibilities. & 2.24 & 1.34 & 1.53 & 0.96 \\
\hline Q13: It fuels an interest I have to understand more about sex. & 2.18 & 1.33 & 1.50 & 0.93 \\
\hline \multicolumn{5}{|l|}{ Factor 2: Emotional Avoidance } \\
\hline Q2: It provides an opportunity to be distracted from life's challenges. & 2.05 & 1.21 & 1.41 & 0.80 \\
\hline Q3: I turn to it when I'm feeling down, sad, or lonely. & 2.01 & 1.27 & 1.34 & 0.79 \\
\hline Q10: I use it to change my mood when I am anxious, stressed or angry. & 1.98 & 1.24 & 1.34 & 0.80 \\
\hline Q12: I use it to avoid feeling uncomfortable or unpleasant emotions. & 2.03 & 1.25 & 1.35 & 0.78 \\
\hline $\begin{array}{l}\text { Q15: I use it to disconnect from unpleasant circumstances or situations } \\
\text { I experience. }\end{array}$ & 1.99 & 1.29 & 1.29 & 0.76 \\
\hline \multicolumn{5}{|l|}{ Factor 3: Excitement-Seeking } \\
\hline Q5: I use it to escape into a fantasy world. & 2.09 & 1.32 & 1.37 & 0.84 \\
\hline Q6: I use it to provide some novelty or variety in my life. & 2.14 & 1.34 & 1.40 & 0.85 \\
\hline Q11: It gives me a sense of excitement. & 2.13 & 1.29 & 1.38 & 0.86 \\
\hline \multicolumn{5}{|l|}{ Factor 4: Sexual Pleasure } \\
\hline Q7: I use it to sexually arouse myself. & 2.09 & 1.28 & 1.38 & 0.87 \\
\hline Q9: I use it to feel physical pleasure. & 2.07 & 1.31 & 1.34 & 0.81 \\
\hline Q14: I use it to help me masturbate for a physical release. & 2.05 & 1.30 & 1.31 & 0.79 \\
\hline
\end{tabular}

Table 2: Difference gender between the means in z-test for two independent samples

\begin{tabular}{|l|c|c|}
\hline \multicolumn{1}{|c|}{ Variable } & Difference & p-Value \\
\hline Factor 1: Sexual Curiosity & 0.6818 & $<0.0001$ \\
\hline Q1: I use it to learn more about a sexual activity. & 0.7435 & $<0.0001$ \\
\hline Q4: I'm curious about what type of sex other people have. & 0.7143 & $<0.0001$ \\
\hline Q8: I use it to expand my knowledge about sexual possibilities. & 0.6756 & $<0.0001$ \\
\hline Q13: It fuels an interest I have to understand more about sex. & 0.6363 & $<0.0001$ \\
\hline Factor 2: Emotional Avoidance & 0.6687 & $<0.0001$ \\
\hline Q2: It provides an opportunity to be distracted from life's challenges. & 0.6402 & $<0.0001$ \\
\hline Q3: I turn to it when I'm feeling down, sad, or lonely. & 0.6815 & $<0.0001$ \\
\hline Q10: I use it to change my mood when I am anxious, stressed or angry. & 0.693 & $<0.0001$ \\
\hline Q12: I use it to avoid feeling uncomfortable or unpleasant emotions. & 0.7236 & $<0.0001$ \\
\hline Q15: I use it to disconnect from unpleasant circumstances or situations I experience. & \multicolumn{2}{|l|}{} \\
\hline Factor 3: Excitement-Seeking & 0.7475 & $<0.0001$ \\
\hline Q5: I use it to escape into a fantasy world. & 0.7476 & $<0.0001$ \\
\hline Q6: I use it to provide some novelty or variety in my life. & \\
\hline Q11: It gives me a sense of excitement. & \\
\hline Factor 4: Sexual Pleasure & & \\
\hline
\end{tabular}


Q7: I use it to sexually arouse myself.

Q9: I use it to feel physical pleasure.

Q14: I use it to help me masturbate for a physical release.

\section{CONCLUSION}

The reason for this study is to identify the factors of using pornography between genders in social media. A total of 1340 respondent that come from the youth of man and women between age 15 until 40 years old in Malaysia was involved in data collection procedure. The respondent has been distributed a set of questionnaire that includes a profile of sexual behavior and using the Pornography Consumption Inventory (PCI) questionnaire. Z-test is applied in this study to determine differences between genders in factor use of pornographic displays in social media. The outcome of this research that was being analyzed using Z-test show a significant difference of mean score from four factors which are Sexual Curiosity (SC), Emotional Avoidance (EA), Excitement Seeking (ES), and Sexual Pleasure (SP) between gender.

\section{ACKNOWLEDGMENT}

The authors thank the Research and Development Management Unit, University of Sultan Zainal Abidin (UniSZA), Kuala Terengganu for providing the research grant for the study.

\section{REFERENCES}

1. G. Hawkins, and F. E. Zimring, "Freedom of expression and the public law of pornography," in Pornography in a Free Society, G. Hawkins and F. E. Zimring, Ed. England: Cambridge University Press, 1991, pp. 109-146.

2. C. T. Carr, and R. A. Hayes, "Social media: Defining, developing, and divining," Atlantic Journal of Communication, 23(1), 2015, pp. 46-65.

3. M. Vergeer, and B. Pelzer, "Consequences of media and Internet use for offline and online network capital and well-being. A causal model approach," Journal of Computer-Mediated Communication, 15(1), 2009, pp. 189-210.

4. D. E. Putnam, "Initiation and maintenance of online sexual compulsivity: Implications for assessment and treatment," CyberPsychology \& Behavior, 3(4), 2000, pp. 553-563.

5. A. Amin, and Y. Ibrahim, "Model of sustainable community participation in homestay program," Mediterranean Journal of Social Sciences, 6(3 S2), 2015, pp. 539-545.

6. B. Wellman, J. Salaff, D. Dimitrova, L. Garton, M. Gulia, and C. Haythornthwaite, "Computer networks as social networks: Collaborative work, telework, and virtual community," Annual Review of Sociology, 22(1), 1996, pp. 213-238.

7. M. H. Abdullah, H. Juahir, F. Lananan, M. K. A. Kamarudin, A. Ghazali, A. Azemin, N. J. A. Wahab, S. M. Mat-Rasid, and M. H. M. Saad, "Pattern recognition of Melaleuca Cajuputi powell essential oils fingerprint in Terengganu, Malaysia using chemometric approach," International Journal of Engineering and Technology, 7(3.14), 2018, pp. 132-138.

8. A. B. H. M. Maliki, M. R. Abdullah, H. Juahir, F. Abdullah, N. A. S. Abdullah, R. M. Musa, S. M. MatRasid, A. Adnan, N. A. Kosni, W. S. A. W. Muhamad, and N. A. M. Nasir, "A multilateral modelling of Youth Soccer
Performance Index (YSPI)," IOP Conference Series: Materials Science and Engineering, 342, 2018, pp. 1-9.

9. N. I. Yusoff, M. R. Abdullah, H. Juahir, J. L. F. Lee, S. M. Mat-Rasid, N. A. Kosni, and M. K. Zawi, "The effect of residence area on motor skill development among children," Indian Journal of Public Health Research \& Development, 10(3), 2019, pp. 614-618.

10. M. S. N. Abu Hassan, M. K. A. Kamarudin, M. H. M. Saad, N. A. Wahab, U. H. N. A. Sabri, W. N. W. Hashin, N. S. Wahab, R. N. S. R. M. Yusoh, and N. A. F. Yusoff, "Death rate analysis due to suicide," International Journal of Engineering and Technology, 7(4.34), 2018, pp. 56-60.

11. A. Norzaida, M. R. Siti Musliha, M. D. Zalina, and A. H. Syafrina, "Probability distributions comparative analysis in assessing rainfall process in time and space," International Journal of Civil Engineering and Technology, 8(10), 2017, pp. 1679-1688.

12. A. B. H. M. Maliki, M. R. Abdullah, H. Juahir, W. S. A. W. Muhamad, N. A. M. Nasir, R. M. Musa, S. M. MatRasid, A. Adnan, N. A. Kosni, F. Abdullah, and N. A. S. Abdullah, "The role of anthropometric, growth and maturity index (AGaMI) influencing youth soccer relative performance," IOP Conference Series: Materials Science and Engineering, 342, 2018, pp. 1-9.

13. M. S. N. A. Hassan, A. Z. Azhar, N. Kamaruddin, and A. Mohamad, "Perspective of Malaysian youths towards homosexuals," Indian Journal of Public Health Research and Development, 10(4), 2019, pp. 747-751.

14. B. Weijters, E. Cabooter, and N. Schillewaert, "The effect of rating scale format on response styles: The number of response categories and response category labels," International Journal of Research in Marketing, 27(3), 2010, pp. 236-247.

15. K. Daneback, B. Træen, and S. A. Månsson, "Use of pornography in a random sample of Norwegian heterosexual couples," Archives of Sexual Behavior, 38(5), 2009, pp. 746-753.

16. D. N. Stewart, and D. M. Szymanski, "Young adult women's reports of their male romantic partner's pornography use as a correlate of their self-esteem, relationship quality, and sexual satisfaction," Sex Roles, 67(5-6), 2012, pp. 257-271.

17. F. O. Poulsen, D. M. Busby, and A. M. Galovan, "Pornography use: Who uses it and how it is associated with couple outcomes," Journal of Sex Research, 50(1), 2013, pp. 72-83.

18. A. J. Bridges, and P. J. Morokoff, "Sexual media use and relational satisfaction in heterosexual couples," Personal Relationships, 18(4), 2010, pp. 562-585.

19. K. L. Derbyshire, and J. E. Grant, "Compulsive sexual behavior: A review of the literature," Journal of Behavioral Addictions, 4(2), 2015, pp. 37-43. 